\title{
Nasal hyperresponsiveness to histamine induced by repetitive exposure to cedar pollen in guinea-pigs
}

\author{
N. Mizutani*, T. Nabe*, K. Sasaki*, H. Takenaka**, S. Kohno*
}

Nasal hyperresponsiveness to histamine induced by repetitive exposure to cedar pollen in guinea-pigs. N. Mizutani, T. Nabe, K. Sasaki, H. Takenaka, S. Kohno. (C)ERS Journals Ltd 1999.

ABSTRACT: Nasal hyperresponsiveness is one of the characteristic features of the pathogenesis of allergic rhinitis. This study examined whether repetitive inhalation of antigen (Japanese cedar pollen) led to the development of nasal hyperresponsiveness to histamine in sensitized conscious guinea-pigs.

Guinea-pigs were repeatedly challenged by pollen inhalation once every week following sensitization by means of intranasal application of pollen extract plus aluminium hydroxide. The upper airways obstruction (increase in specific airway resistance (sRaw)) in response to intranasally instilled histamine was measured as an index of nasal (hyper)responsiveness.

The hyperresponsiveness to histamine gradually developed with repeated pollen inhalation challenge, and the airway response at the 20th and 24th challenges was three to four orders of magnitude higher than that in nonsensitized animals. Similar degrees of hyperresponsiveness were observed at $10 \mathrm{~h}$ and 2 days after a pollen inhalation challenge, but the hyperresponsiveness had almost disappeared by day 7 . The increased responsiveness was suppressed by pretreatment with mepyramine but not with atropine. The maximum $s R$ aw, which was observed $10 \mathrm{~min}$ after histamine instillation, was largely blocked by naphazoline. Hyperresponsiveness was hardly observed on methacholine instillation.

The present allergic rhinitis model, showing marked nasal hyperresponsiveness to histamine after repeated intranasal allergen challenge in guinea pigs, should be useful for investigating the pathogenesis of allergic rhinitis.

Eur Respir J 1999; 14: 1368-1375.
*Dept of Pharmacology, Kyoto Pharmaceutical University, 5 Nakauchi, Misasagi, Yamashina, Kyoto 607-8414, Japan. **Dept of Otorhinolaryngology, Osaka Medical College, Takarsuki, Osaka 5698686, Japan.

Correspondence: S. Kohno, Dept of Pharmacology, Kyoto Pharmaceutical University, 5 Nakauchi, Misasagi, Yamashina, Kyoto 607-8414, Japan, Fax: 81 755954764

\section{Keywords: Allergic rhinitis}

histamine

hyperresponsiveness

nasal blockage

pollen

Received: November 231998

Accepted after revision August 81999

This study was supported, in part, by a Grant-in-Aid for Scientific Research (c) (09672263) from the Ministry of Education, Science, Sports and Culture of Japan.
Nasal hyperresponsiveness is one of the major disorders in patients suffering from allergic rhinitis, which is characterized by symptoms of rhinitis in response to exposure to daily life stimuli such as cold air, hot spicy food, dust and fumes. When patients with upper airway hyperresponsiveness are challenged by intranasal application of histamine, sneeze, rhinorrhoea and nasal airway obstruction are more evident than in healthy individuals [1]. In particular, $>80 \%$ of patients with perennial rhinitis show obvious nasal hyperresponsiveness to nonspecific stimuli, suggesting that repetitive exposure to allergen increases sensitivity to not only that allergen but also other stimuli [2]. Although the mechanism of the occurrence of hyperresponsiveness in the upper airways as well as that in the lower airway has been the subject of considerable study, its details are still unclear. The mechanism of upper airway hyperresponsiveness has mainly been investigated in rhinitis patients [3-6]. However, owing to the limitations of clinical research, an adequate experimental animal model is indispensable for investigating the mechanism that brings about the symptom of rhinitis.

Recently, an allergic rhinitis model developed by repetitive inhalation challenge with quantitative amounts of Japanese cedar pollen as antigen in sensitized guinea-pigs was reported [7]. Following intranasal sensitization by instillation of the antigen and aluminium hydroxide adjuvant, the animal develops not only increasing levels of specific anaphylactic antibodies in its serum but also more frequent sneezes and exhibits biphasic elevation of specific airway resistance (sRaw) in response to repeated pollen inhalation challenge.

In the present study, experimental allergic rhinitis was further characterized in terms of the acquisition of nasal hyperresponsiveness to histamine, and pharmacological analyses were performed in order to elucidate the part of the mechanism underlying the occurrence of hyperresponsiveness.

\section{Materials and methods}

\section{Animals}

Male, 3-week-old, Hartley guinea-pigs weighing 250$300 \mathrm{~g}$ were purchased from Japan SLC (Hamamatsu, Japan). The animals were housed in an air-conditioned room at a temperature of $23 \pm 1{ }^{\circ} \mathrm{C}$ and $60 \pm 10 \%$ humidity, illuminated 08:00-20:00 h. They were fed a standard laboratory diet and given water ad libitum. The first sensitization was started 2 weeks after purchase. Animals were examined in the conscious condition, and, for sensitization, they were given local anaesthesia. 
This animal study was approved by the Experimental Animal Research Committee at Kyoto Pharmaceutical University.

\section{Reagents}

Reagents and their sources were as follows: Japanese cedar (Cryptomeria japonica) pollen (donated from the laboratory of Torii Pharmaceutical Co. Ltd., Chiba, Japan), histamine dihydrochloride and methacholine chloride (MCh) (Wako Pure Chemicals, Osaka, Japan), mepyramine maleate and atropine sulphate (Nacalai Tesque, Kyoto, Japan), and naphazoline hydrochloride (Sigma Chemicals, St. Louis, MO, USA). The other reagents used were the highest grade of commercial product available.

$\mathrm{Al}(\mathrm{OH})_{3}$ gels were prepared from $0.5 \mathrm{~N} \mathrm{NaOH}$ and 0.5 $\mathrm{N} \mathrm{Al}_{2}\left(\mathrm{SO}_{4}\right)_{3}$ as previously described [8].

\section{Study design}

Guinea-pigs were repeatedly challenged once every week with cedar pollen following sensitization with pollen extract plus $\mathrm{Al}(\mathrm{OH})_{3}$. The time-course of change in $\mathrm{s} R \mathrm{aw}$ after intranasal instillation of histamine was measured 2 days after the 13th pollen inhalation challenge in sensitized guinea-pigs. The nasal responsiveness to various concentrations of histamine and $\mathrm{MCh}$ in the sensitized guineapigs was evaluated 2 days after the 20th and the 22nd challenges, respectively, in comparison with that in the nonsensitized animal. Furthermore, the nasal hyperresponsiveness to histamine and MCh was evaluated $10 \mathrm{~h}$ and 2 and 7 days after the 24th and the 26th antigen provocation, respectively. In a separate group of sensitized animals, time-related changes in nasal responsiveness to histamine during the course of repetitive antigen inhalation challenges were investigated using the animals 2 days after the respective 1st-20th pollen challenges. The effects of mepyramine (a histamine receptor $\left(\mathrm{H}_{1}\right)$ antagonist), atropine (a cholinergic receptor antagonist) and naphazoline (an $\alpha$-adrenergic) on nasal hyperresponsiveness to histamine were examined on the 2 nd day after the respective 22nd, 24th and 26th challenges. The possible participation of nasal vascular permeability in the hyperresponsiveness to histamine was also assessed by means of dye leakage method.

\section{Preparation of Japanese cedar pollen extract}

The cedar pollen extract used for the sensitization was prepared according to a previously described method [7]. In brief, the pollen was suspended at $100 \mathrm{mg} \cdot \mathrm{mL}^{-1}$ in physiological saline and allowed to stand for $18 \mathrm{~h}$ at $4{ }^{\circ} \mathrm{C}$ with mild stirring. The suspension was then centrifuged $(1,700 \times g, 15 \mathrm{~min})$, and the resultant supernatant used as the sensitization antigen; this was stored at $-80^{\circ} \mathrm{C}$ until use. The protein concentration in the solution was quantified according to the method of BENSADOUN and WEINSTEIN [9]; it was estimated to be $500 \mu \mathrm{g}$ protein $\cdot \mathrm{mL}^{-1}$.

\section{Sensitization and challenge}

As previously described [7], guinea-pigs were bilaterally intranasally sensitized by instillation with $3 \mu \mathrm{L}$ per nostril of cedar pollen extract adsorbed on $\mathrm{Al}(\mathrm{OH})_{3}$ gel at $1 \mu \mathrm{g}$ protein.mg $\mathrm{Al}(\mathrm{OH})_{3}{ }^{-1} \cdot 10 \mu \mathrm{L}^{-1}$ twice daily for 7 days. Prior to each sensitization, the upper airway mucosal surface was topically anaesthetized by subjecting the animal to a 2-min inhalation of a $4 \%$ lignocaine hydrochloride mist (Fujisawa Pharmaceutical Co. Ltd., Osaka, Japan), which was generated via an ultrasonic nebulizer (NE-U12; Omron, Osaka, Japan). This procedure was conducted in order to obtain effective sensitization by means of prolonged retention of the antigen plus $\mathrm{Al}$ $(\mathrm{OH})_{3}$ in the nasal cavity: it has been reported that lignocaine reduces the ciliary beat frequency of the guinea-pig airway in vitro [10] and that topical anaesthetic drugs do not decrease mucosal absorbency [11]. Then, the sensitized animals were bilaterally intranasally challenged once every week by quantitative inhalation of the cedar pollen at a dose of $1.8 \mathrm{mg} \cdot$ nostril $^{-1}$ via a handmade inhalation apparatus [12]. When the pollen was applied to both nostrils of spontaneously breathing guinea-pigs, almost all of the inhaled pollen was trapped in the upper airways; 10 and $60 \mathrm{~min}$ after the inhalation, 81 and $55 \%$ of the pollen, respectively, was found in the upper airway, but less than $0.001 \%$ reached the lower airways [12]. The decreased amount of pollen in the upper airway with time after inhalation was mostly accounted for by pollen cell walls found in the oesophagus and stomach.

When nonsensitized guinea-pigs were forced to inhale pollen, the guinea-pigs showed no increases in either $\mathrm{s} R \mathrm{aw}$ or responsiveness to histamine (data not shown).

\section{Measurement of specific airway resistance}

sRaw was measured by means of a two-chambered double-flow plethysmographic system according to the method of PENNOCK et al. [13]. In brief, the animal was placed with its neck extending through the partition of a twochambered box, and sRaw was measured using a Data analyser Pulmos-I (Medical Interface Project Station, Osaka, Japan) and a PC 9801 FA computer (NEC, Tokyo, Japan) after monitoring the airflow via sensors attached to both the front and rear chambers.

\section{Nasal responsiveness to histamine and methacholine chloride}

In order to estimate the time-course of the response to histamine in the nasal airway, $10 \mu \mathrm{L} \cdot$ cavity $^{-1} 10^{-4} \mathrm{M}$ histamine was instilled into both nasal cavities of the conscious sensitized guinea-pigs 2 days after the 13th pollen inhalation challenge, and then sRaw was monitored for $60 \mathrm{~min}$.

Two days after the 20th and the 22nd inhalation challenges, the airway responsiveness to, respectively, histamine and MCh of the sensitized guinea-pigs was measured. The time-course of changes in nasal hyperresponsiveness to histamine and $\mathrm{MCh}$ following antigen challenge in sensitized guinea-pigs were evaluated $10 \mathrm{~h}$ and 2 and 7 days after the 24th and 26th antigen provocations, respectively.

The hyperresponsiveness tests described above were performed according to the following procedures: saline $\left(10 \mu \mathrm{L} \cdot\right.$ cavity $\left.^{-1}\right)$ and increasing doses of histamine or MCh were consecutively applied bilaterally to the nasal cavities of the sensitized guinea-pigs or the nonsensitized guineapigs at an interval of $20 \mathrm{~min}$. sRaw was measured before 
saline instillation and 10 min after each dose of agonist. Time-related changes in nasal hyperresponsiveness to histamine during the course of repetitive antigen inhalation challenges were evaluated by instillation of $10^{-4} \mathrm{M}$ histamine into both nasal cavities 2 days after the 1st-20th pollen challenges. Baseline and increased sRaw were measured before and $10 \mathrm{~min}$ after histamine application, respectively.

Effects of drugs on the increased specific airway resistance induced by histamine and methacholine chloride

In order to evaluate the effects of antihistaminic drugs and anti-cholinergic drugs on nasal hyperresponsiveness to histamine, mepyramine $\left(10 \mathrm{mg} \cdot \mathrm{kg}^{-1}\right.$, p.o. $)$ and atropine $(1$ $\mathrm{mg} \cdot \mathrm{kg}^{-1}$, p.o.) were administered $1 \mathrm{~h}$ before application of saline to the sensitized group on the 2 nd day after the respective 22 nd and 24 th challenges.

On the 2nd day after the 26th challenge, naphazoline $\left(0.1 \mathrm{mg} \cdot \mathrm{kg}^{-1}\right.$, i.v. $)$, an $\alpha$-adrenergic, was administered 8 min after the application of histamine $\left(10^{-4} \mathrm{M}\right)$ or $\mathrm{MCh}$ $\left(10^{-2} \mathrm{M}\right)$. sRaw was measured just before and 2 min after $\alpha$-adrenergic treatment.

\section{Measurement of the change in vascular permeability}

Plasma extravasation into the lamina propria and luminal entry as a result of histamine instillation were evaluated. Evans blue $\left(1 \%, 1 \mathrm{~mL} \cdot \mathrm{kg}^{-1}, i . v\right.$. $)$ was administered to the sensitized guinea-pigs 2 days after the 28th pollen inhalation. One hour later, $10^{-4} \mathrm{M}$ histamine was instilled into both nasal cavities in the same manner as described above. Ten minutes after instillation, the guinea-pigs were sacrificed by exsanguination under pentobarbital anaesthesia $\left(40 \mathrm{mg} \cdot \mathrm{kg}^{-1}, i . v\right.$.). The following procedures were carried out for quantification of the dye that had leaked into the luminal entry and lamina propria. To quantify the dye in the luminal entry, the nasal cavities were perfused with 2 $\mathrm{mL} \cdot$ animal $^{-1}$ saline through the pharynx and the perfusate was collected. The perfusate was centrifuged $(1,700 \times g$, $10 \mathrm{~min}$ ), and then the amount of Evans blue in the supernatant measured colorimetrically at $620 \mathrm{~nm}$. To qualify the dye in the lamina propria, the nasal mucosal tissue was removed after perfusion of the head with $40 \mathrm{~mL} \cdot$ animal $^{-1}$ saline through the carotid artery. The tissue was treated with alkali $\left(1.2 \mathrm{~N} \mathrm{KOH}, 18 \mathrm{~h}\right.$ at $37^{\circ} \mathrm{C}, 2 \mathrm{~mL}$-animal $\left.{ }^{-1}\right)$, the suspension centrifuged for $10 \mathrm{~min}$ at $1,700 \times g$ and the dye in the supernatant colorimetrically measured at $620 \mathrm{~nm}$, according to the method of KaTAYAMA et al. [14]. For the controls, nonsensitized saline-instilled and nonsensitized histamine-instilled groups were prepared.

\section{Statistical analyses}

Statistical analyses were performed by means of oneway analysis of variance. If a significant difference was detected, the individual group difference was determined using Bonferroni's multiple test. A p-value $<0.05$ was considered statistically significant.

\section{Results}

Time-course of change in specific airway resistance after histamine instillation

Figure 1 shows the time-course of the change in sRaw after instillation of $10^{-4} \mathrm{M}$ histamine into both nasal cavities of the sensitized guinea-pigs 2 days after the 13th pollen inhalation challenge. Instillation of histamine caused a swift elevation of $\mathrm{s} R$ aw which peaked at $10 \mathrm{~min}$, followed by gradual diminution until $60 \mathrm{~min}$ after instillation. However, a moderate increase in sRaw was still detectable at $60 \mathrm{~min}$. Based on these results, sRaw was measured $10 \mathrm{~min}$ after histamine and $\mathrm{MCh}$ instillation.

\section{Nasal responsiveness to histamine and methacholine chloride}

The nasal responsiveness to histamine and MCh of the sensitized guinea-pigs was evaluated 2 days after the respective 20th and 22nd pollen challenges in comparison with that of the nonsensitized animals. These results are shown in figure 2 . In the sensitized animals, $10^{-8}$ and $10^{-6}$ $\mathrm{M}$ histamine tended to elevate $\mathrm{s} R \mathrm{aw}$, and significant dosedependent increases were observed at $10^{-4}$ and $10^{-2} \mathrm{M}$. In contrast, the nonsensitized guinea-pigs showed only modest increases, even at $10^{-2} \mathrm{M}$. The dose/response curve for histamine indicated that the sensitized guinea-pigs were 3-4 orders of magnitude more sensitive to histamine than the nonsensitized animals. Conversely, no apparent difference was seen between the two groups in the doserelated changes in $\mathrm{s}$ aw in response to $\mathrm{MCh}$.

Time-course of change in nasal hyperresponsiveness to histamine and methacholine chloride after pollen inhalation challenge

The time-course of changes in nasal hyperresponsiveness of the sensitized guinea-pigs to histamine and MCh were evaluated $10 \mathrm{~h}$ and 2 and 7 days after the respective

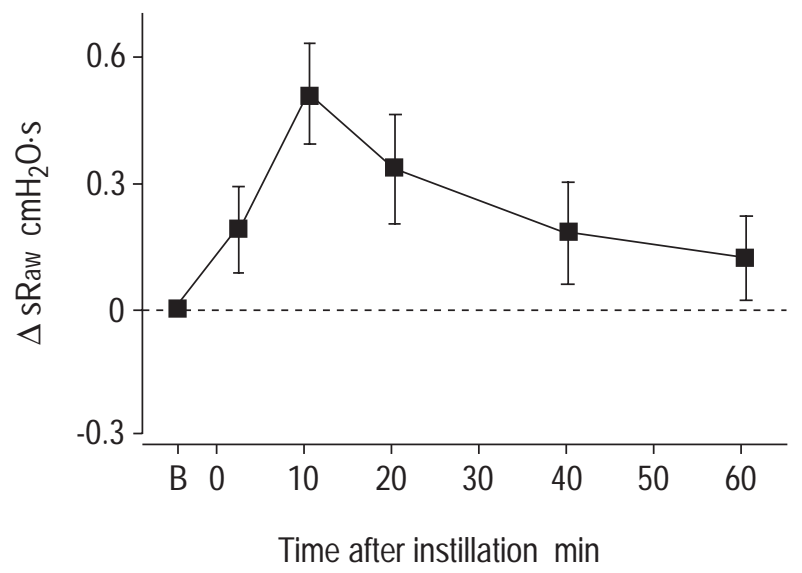

Fig. 1. - Time course of the increase in specific airway resistance (sRaw) induced by intranasal instillation of histamine $\left(10^{-4}\right)$ in sensitized guinea-pigs 2 days after the 13 th cedar pollen inhalation challenge. Data are presented as mean \pm SEM $(n=10) . \Delta$ : change; B: before histamine instillation. 

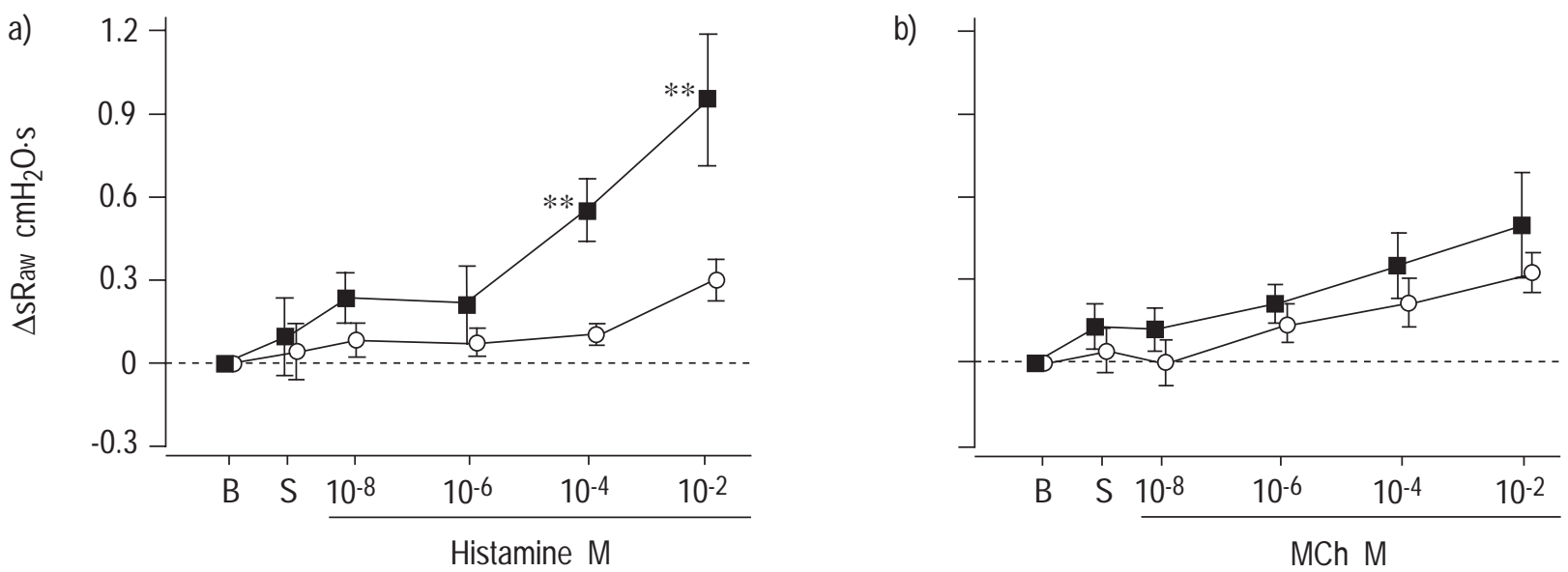

Fig. 2. - Nasal responsiveness to: a) histamine; and b) methacholine (MCh) in sensitized $(\mathbb{a})$ and nonsensitized $(O)$ guinea-pigs 2 days after the 20th (histamine) or the 22 nd cedar pollen inhalation challenge $(\mathrm{MCh})$. Data are presented as mean \pm SEM $(\mathrm{n}=12)$. Specific airway resistances (sRaw) before saline instillation (B) were $1.76 \pm 0.21$ and $1.79 \pm 0.09 \mathrm{cmH}_{2} \mathrm{O} \cdot \mathrm{s}(\mathrm{Ns})$ for nonsensitized and sensitized animals (a) and $1.81 \pm 0.13$ and $1.94 \pm 0.17 \mathrm{cmH} \mathrm{H}_{2} \mathrm{O} \cdot \mathrm{s}$ (NS) (b). $\Delta$ : change; $\mathrm{S}$ : saline instillation. $*{ }^{* *}: \mathrm{p}<0.05, \mathrm{p}<0.01$ compared to the nonsensitized group.

24th and 26th antigen challenges in comparison with nonsensitized group. Figures 3 and 4 show the results. In the sensitized group, the dose/sRaw response curve for histamine at $10 \mathrm{~h}$ was shifted to the left by 3-4 orders of magnitude, which was similar to that obtained on the 2 nd day. However, this marked hyperresponsiveness had almost disappeared by the 7th day. Conversely, no apparent difference was seen between the nonsensitized and sensitized groups in the dose/sRaw response to MCh at 10 h, or 2 or 7 days.

Nasal responsiveness to histamine during the course of repetitive challenges

Table 1 shows the baseline sRaw 2 days after the respective 1st-20th pollen challenges in the sensitized group, which were measured before histamine instillation. The $s R$ aw were not significantly different from the nonsensitized group at any time.

Figure 5 shows the results of evaluating nasal responsiveness to $10^{-4} \mathrm{M}$ histamine 2 days after the respective
1 st-20th pollen challenges in sensitized guinea-pigs. At the 1st-3rd pollen inhalations, histamine caused moderate changes in the sensitized group that were greater than those in the nonsensitized group, but these increases were not significantly different from those in the nonsensitized group. At the 4th pollen challenge, significant hyperresponsiveness was obtained. The degree of hyperresponsiveness was elevated in an antigen challenge-dependent fashion until the 20th antigen challenge.

Effects of mepyramine and atropine on the increased specific airway resistance induced by histamine

Figure 6 shows the effects of mepyramine and atropine on nasal hyperresponsiveness to histamine. Pretreatment with $10 \mathrm{mg} \cdot \mathrm{kg}^{-1}$ mepyramine suppressed the hyperresponsiveness to a level similar to that found in the nonsensitized group. The inhibitory action of the drug against the responses induced by both $10^{-6}$ and $10^{-2} \mathrm{M}$ histamine was significant. However, pretreatment with $1 \mathrm{mg} \cdot \mathrm{kg}^{-1}$ atropine had no inhibitory effect on the response.
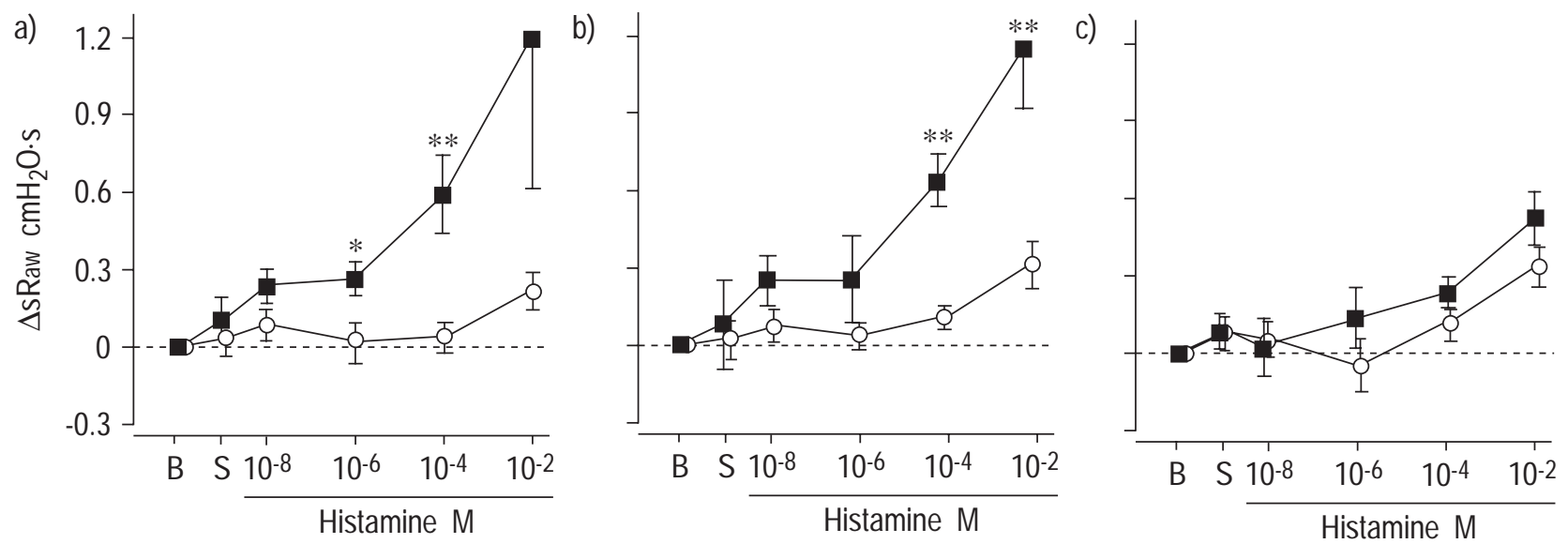

Fig. 3. - Time course of changes in nasal responsiveness to histamine: a) $10 \mathrm{~h}$; b) 2 days; and c) 7 days after the 24 th cedar pollen inhalation challenge in sensitized $(\square)$ and nonsensitized $(O)$ guinea-pigs. Data are presented as mean $\pm \operatorname{SEM}(\mathrm{n}=12)$. Specific airway resistances ( $\mathrm{s} R \mathrm{aw})$ before saline instillation (B) were $1.50 \pm 0.13$ and $1.88 \pm 0.15 \mathrm{cmH}_{2} \mathrm{O} \cdot \mathrm{s}(\mathrm{NS})$ in nonsensitized and sensitized animals (a), $1.56 \pm 0.13$ and $1.36 \pm 0.08 \mathrm{cmH} \mathrm{H}_{2} \mathrm{O} \cdot \mathrm{s}(\mathrm{NS})(\mathrm{b})$ and $1.71 \pm 0.12$ and $1.64 \pm 0.09 \mathrm{cmH}_{2} \mathrm{O} \cdot \mathrm{s}$ (NS) (c). $\Delta$ : change; $\mathrm{S}$ : saline instillation. ${ }^{*}, * *$ : $<<0.05, \mathrm{p}<0.01$ compared to the nonsensitized group. 

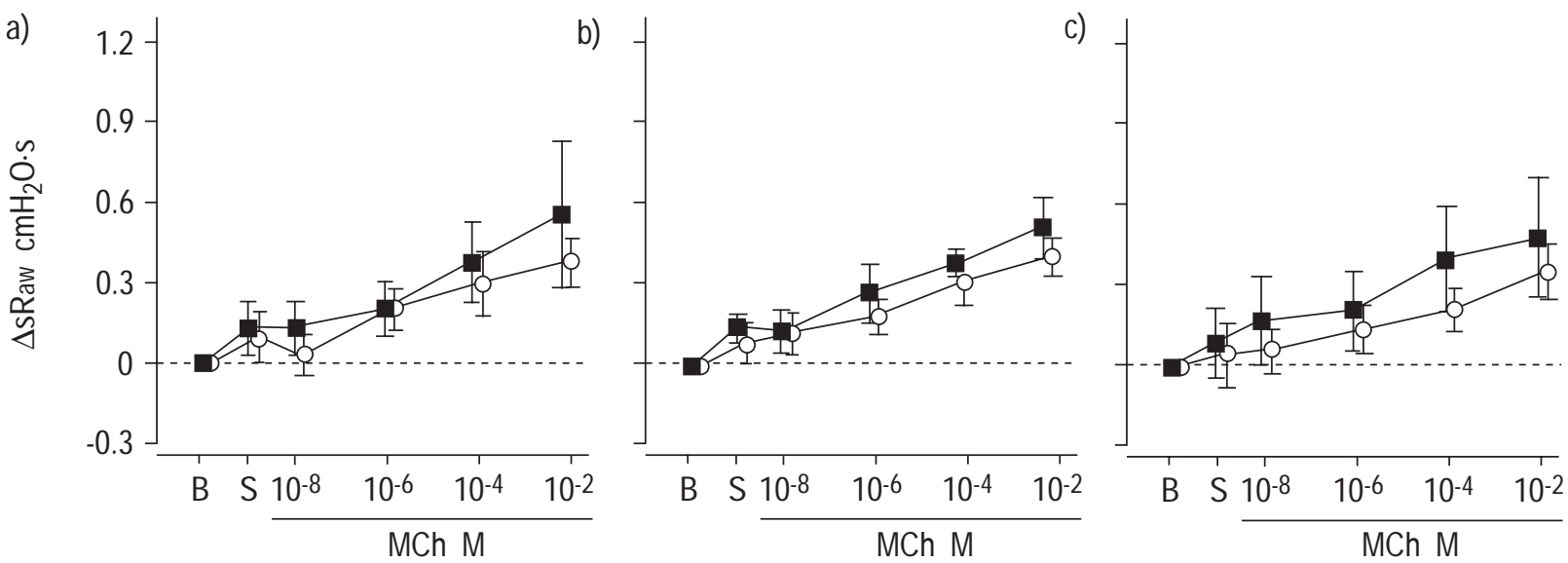

Fig. 4. - Time course of changes in nasal responsiveness to methacholine (MCh): a) $10 \mathrm{~h}$; b) 2 days; and c) 7 days after the 26 th cedar pollen inhalation challenge in sensitized $(\square)$ and nonsensitized $(\bigcirc)$ guinea-pigs. Data are presented as mean $\pm \operatorname{SEM}(\mathrm{n}=12)$. Specific airway resistances $(\mathrm{s} R$ aw) before saline instillation (B) were $1.45 \pm 0.07$ and $1.65 \pm 0.15 \mathrm{cmH}_{2} \mathrm{O} \cdot \mathrm{s}(\mathrm{NS})$ in nonsensitized and sensitized animals (a), $\left.1.50 \pm 0.13 \mathrm{and} 1.35 \pm 0.09 \mathrm{cmH} \mathrm{H}_{2} \mathrm{O} \cdot \mathrm{s}\right)(\mathrm{Ns})(\mathrm{b})$ and $1.53 \pm 0.11$ and $1.78 \pm 0.17 \mathrm{cmH}_{2} \mathrm{O} \cdot \mathrm{s}$ (NS) (C) $\Delta$ : change; $\mathrm{S}$ : saline instillation.

Effect of naphazoline on spontaneous and histamineand methacholine chloride-induced increased in specific airway resistance

Figure 7 shows the effects of intravenous naphazoline on spontaneous sRaw in the nonsensitized group and the elevated $\mathrm{s} R$ aw induced by histamine $\left(10^{-4} \mathrm{M}\right)$ and $\mathrm{MCh}$ $\left(10^{-2} \mathrm{M}\right)$ in the sensitized group 2 days after the respective 24th and 26th challenges. In the nonsensitized group without histamine instillation, naphazoline potently lowered the spontaneous sRaw (by $\sim 0.6 \mathrm{cmH}_{2} \mathrm{O} \cdot \mathrm{s}$. Conversely, in the sensitized group, the drug not only completely blocked the increased sRaw induced by histamine, but also lowered the normal level (by $\sim 0.35 \mathrm{cmH}_{2} \mathrm{O} \cdot \mathrm{s}$ ). However, the degree of lowering in the sensitized group was slightly weaker than that in the nonsensitized one. Naphazoline blocked the increase in $\mathrm{s} R$ aw induced by instillation of MCh to a level similar to that observed in the nonsensitized, $\alpha$-adrenergic-treated group.

\section{Nasal vascular permeability response to histamine}

Table 2 shows the nasal vascular permeability induced by $10^{-4} \mathrm{M}$ histamine instillation 2 days after the 28th pollen challenge in the sensitized group. When histamine was instilled into the nasal cavities of nonsensitized gui-

Table 1. - Specific airway resistance (sRaw) 2 days after allergen challenge

\begin{tabular}{lcc}
\hline \multirow{2}{*}{$\begin{array}{c}\text { Allergen challenge } \\
\text { No. }\end{array}$} & \multicolumn{2}{c}{$\mathrm{sRaw} \mathrm{cmH}_{2} \mathrm{O} \cdot \mathrm{s}$} \\
\cline { 2 - 3 } & Nonsensitized group & Sensitized group \\
\hline 1 & $1.21 \pm 0.05$ & $1.30 \pm 0.10$ \\
2 & $1.56 \pm 0.06$ & $1.43 \pm 0.05$ \\
3 & $1.49 \pm 0.06$ & $1.42 \pm 0.05$ \\
4 & $1.54 \pm 0.08$ & $1.60 \pm 0.06$ \\
5 & $1.40 \pm 0.07$ & $1.41 \pm 0.03$ \\
7 & $1.57 \pm 0.07$ & $1.44 \pm 0.04$ \\
10 & $1.81 \pm 0.06$ & $1.71 \pm 0.06$ \\
13 & $1.31 \pm 0.07$ & $1.31 \pm 0.05$ \\
20 & $1.88 \pm 0.15$ & $1.76 \pm 0.21$ \\
\hline
\end{tabular}

Data are presented as mean $\pm \operatorname{SEM}(\mathrm{n}=12)$. nea-pigs, no changes in the amount of dye in the airway tissues were observed $10 \mathrm{~min}$ after instillation. However, in the sensitized group, histamine induced significant increases in the amount of Evans blue in both the lamina propria and luminal entry, by 10 and $0.35 \mu \mathrm{g} \cdot$ animal $^{-1}$, respectively, compared to nonsensitized saline-instilled group.

As the concentrations of Evans blue and total protein in the plasma were estimated to be $102 \pm 7.4 \mu \mathrm{g} \cdot \mathrm{mL}^{-1} \quad(\mathrm{n}=6)$ and $50.4 \pm 0.9 \mathrm{mg} \cdot \mathrm{mL}^{-1}(\mathrm{n}=6)$ respectively the amount of plasma protein and plasma volume that had leaked into the lamina propria and luminal entry were calculated as $\sim 5$ and $\sim 0.2 \mathrm{mg} \cdot$ animal $^{-1}$ and $\sim 100$ and $\sim 3.5 \mu \mathrm{L} \cdot$ animal $^{-1}$, ,espectively.

\section{Discussion}

In the present study, it was investigated whether nasal hyperresponsiveness, one of the characteristic symptoms of patients suffering from allergic rhinitis, was also observed in the model used when a chemical stimulus,

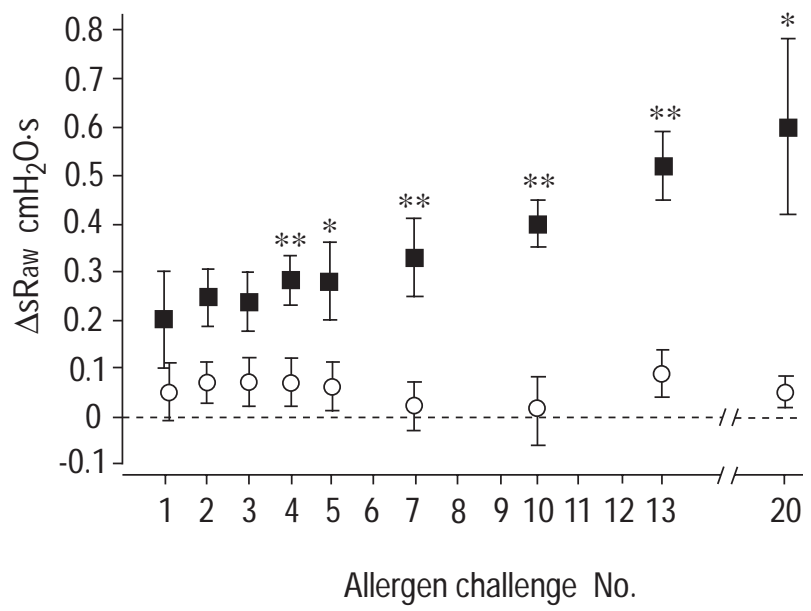

Fig. 5. - Changes in nasal responsiveness to histamine $\left(10^{-4}\right)$ during the course of repetitive challenges in guinea-pigs 2 days after the respective pollen inhalation challenges. Data are presented as mean \pm SEM $(n=12)$. $\bigcirc$ : nonsensitized; $\square$ : sensitized. $\Delta$ sRaw: change in specific airway resistance. ${ }^{*},{ }^{*}: \mathrm{p}<0.05, \mathrm{p}<0.01$ compared to the nonsensitized group. 

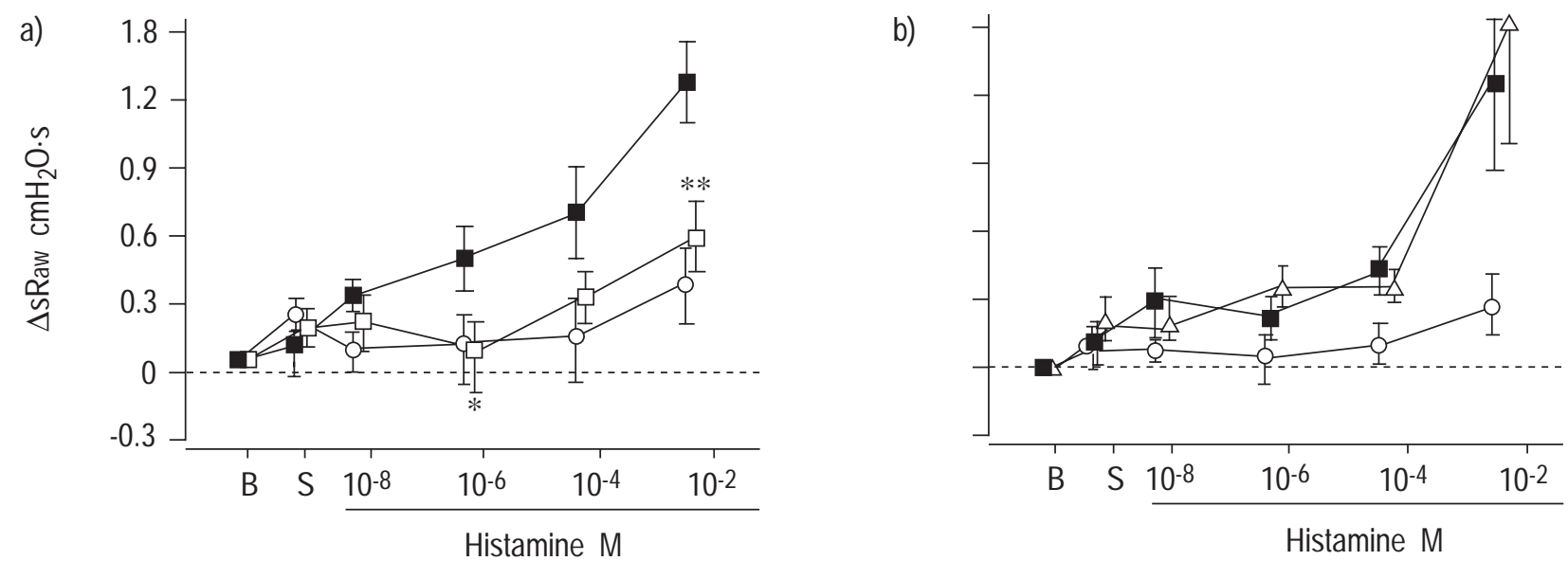

Fig. 6. - Effect of: a) mepyramine $(\square)$ and b) atropine $(\Delta)$ on nasal hyperresponsiveness to histamine in sensitized $(\square)$ guinea-pigs $(\bigcirc$ : nonsensitized guinea-pigs) 2 days after the $22 \mathrm{nd}$ (mepyramine) or the 24 th cedar pollen inhalation challenge (atropine). Mepyramine (10 mg. $\left.\mathrm{kg}^{-1}\right)$ and atropine (1 $\left.\mathrm{mg} \cdot \mathrm{kg}^{-1}\right)$ were administered orally $1 \mathrm{~h}$ prior to the saline instillation. Data are presented as mean \pm SEM $(\mathrm{n}=8-12)$. Specific airway resistances $(\mathrm{s} R$ aw) before saline instillation (B) were $1.86 \pm 0.10,1.95 \pm 0.12$ and $2.04 \pm 0.14 \mathrm{cmH}_{2} \mathrm{O} \cdot \mathrm{s}$ in nonsensitized, sensitized and sensitized drug-treated guinea-pigs respectively (NS) (a) and $2.09 \pm 0.09,1.76 \pm 0.14$ and $1.91 \pm 0.11 \mathrm{cmH}_{2} \mathrm{O} \cdot \mathrm{s}$ (NS) (b) $\Delta$ : change; $\mathrm{S}$ : saline instillation. ${ }^{*}, * *: \mathrm{p}<0.05, \mathrm{p}<0.01 \mathrm{compared}$ to the nonsensitized group.

histamine, was applied to the nasal cavities. Because the guinea-pig functionally respires through the nose but not through the mouth, sRaw can be taken as the total resistance of the upper and lower airways in the animal. It has been reported that the early bronchoconstrictor response is characterized by rapid and shallow breathing in a guinea-pig asthmatic model [15]. When guinea-pigs were forced to inhale a fine mist of histamine solution $\left(10^{-3}-10^{-1} \mathrm{M}\right)$, $\sim 80 \%$ of which was trapped in and acted on the bronchi, rapid and shallow respiration was observed (unpublished data). Conversely, it has been previously reported that the pollen inhalation challenge-induced elevation of $\mathrm{s} R \mathrm{aw}$ correlated well with the decrease in respiratory frequency in the present experimental allergic rhinitis model [7]. A

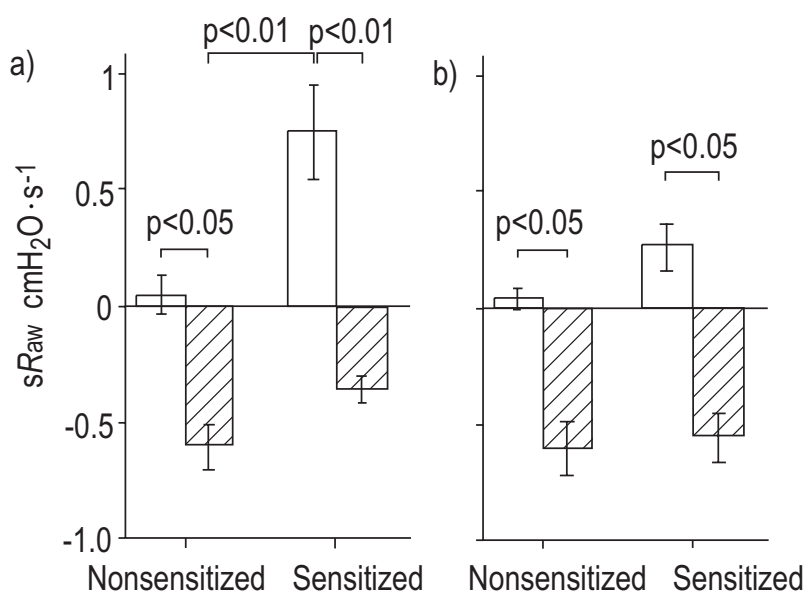

Fig. 7. - Effect of naphazoline on nasal hyperresponsiveness to: a) histamine $\left(10^{-4}\right)$; and b) methacholine chloride $\left(\mathrm{MCh} ; 10^{-2} \mathrm{M}\right)$ in sensitized guinea-pigs 2 days after the 26th pollen inhalation challenge. Naphazoline $\left(\mathscr{U} 0.1 \mathrm{mg} \cdot \mathrm{kg}^{-1}\right)$ was administered intravenously $8 \mathrm{~min}$ after intranasal instillation of histamine or MCh. Changes in specific airway resistance ( $\mathrm{s} R \mathrm{aw}$ ) were measured $2 \mathrm{~min}$ after naphazoline treatment. Data are presented as mean $\pm \operatorname{SEM}(\mathrm{n}=8)$. $\mathrm{s} R$ aw before the instillation were $1.44 \pm 0.12,1.65 \pm 0.15,1.53 \pm 0.11$ and $1.45 \pm 0.07 \mathrm{cmH}_{2} \mathrm{O} \cdot \mathrm{s}$ in nonsensitized, nonsensitized naphazoline-treated, sensitized and nonsensitized naphazoline-treated guinea-pigs respectively (NS) (a) and 1.78 \pm 0.17 , $1.46 \pm 0.04,1.65 \pm 0.15$ and $1.45 \pm 0.03 \mathrm{cmH}_{2} \mathrm{O} \cdot \mathrm{s}$ (Ns) (b). $\Delta$ : change. similar correlation was also observed after intranasal instillation of histamine (data not shown). Furthermore, intranasal instillation of leukotriene $\mathrm{D}_{4}$, a well-known potent airway smooth muscle constrictor, did not have any effect on sRaw, even at high concentration in nonsensitized guinea-pigs (unpublished data, manuscript in preparation). NARITA et al. [16] have reported that $10 \mathrm{~min}$ and $1 \mathrm{~h}$ after application of $100 \mu \mathrm{L}$ Evans blue solution as a nasal drip, most of the dye was found within the nasal cavity, and there was no staining in the larynx, trachea or bronchus. These results and reports indicate that intranasally instilled agonists almost exclusively affect the upper airway, not the lower airway, and that the mechanisms of upper airway obstruction are quite different from those of the lower airways. Therefore, the increase in sRaw induced by histamine instillation, which was chosen as the index for hyperresponsiveness to the agonist, can be considered to reflect upper airway obstruction in the present model.

The intensity of nasal hyperresponsiveness to histamine instillation increased with the number of antigen exposures, and nasal hyperresponsiveness was evident at $10 \mathrm{~h}$ and 2 days, but not at 7 days, following the inhalation provocation. In individuals with pollinosis, in whom the

Table 2. - Amount of Evans blue in the lamina propria and luminal entry following intranasal instillation of histamine in sensitized guinea-pigs

\begin{tabular}{lcc}
\hline & \multicolumn{2}{c}{ Amount of Evans blue $\mu \mathrm{g} \cdot$ animal $^{-1}$} \\
\cline { 2 - 3 } & Lamina propria & Luminal entry \\
\hline $\begin{array}{c}\text { Nonsensitized } \\
\text { saline-instilled }\end{array}$ & $19.9 \pm 3.9$ & $0.40 \pm 0.03$ \\
$\begin{array}{c}\text { Nonsensitized/hista- } \\
\text { mine-instilled }\end{array}$ & $21.4 \pm 2.0$ & $0.41 \pm 0.01$ \\
$\begin{array}{c}\text { Sensitized/histamine } \\
\text { instilled }\end{array}$ & $31.4 \pm 1.4^{*,+}$ & $0.75 \pm 0.17^{*,+}$ \\
\hline
\end{tabular}

Data are presented as mean $\pm \operatorname{SEM}(\mathrm{n}=10) .{ }^{*}: \mathrm{p}<0.05$ compared to nonsensitized/saline-instilled group. ${ }^{+}: \mathrm{p}<0.05$ compared to nonsensitized/histamine-instilled group. 
antigen exposure period and the antigen-free period can clearly be distinguished, nasal symptoms including sneezing, rhinorrhoea and nasal obstruction are markedly enhanced in the pollen season, but no apparent hyperresponsiveness is observed during the off-season [6]. In addition, it is generally acknowledged that when a provocative antigen is kept away from allergic rhinitis patients, their hyperresponsiveness disappears within a couple of weeks. Thus, the occurrence and restoration pattern of the hyperresponsiveness observed in the present model are remarkably similar to those of clinical allergic rhinitis. Furthermore, PRIETO et al. [5] reported that nasal hyperresponsiveness in patients with perennial allergic rhinitis is more evident than that in individuals with seasonal rhinitis, suggesting that repetitive antigen exposure is an important factor in the acquisition of nasal hyperresponsiveness to stimuli. The exposure frequencydependent increase in nasal hyperresponsiveness to histamine shown in the present study further indicates the utility of the present allergic rhinitis model for investigating the detailed mechanism of the induction of nasal hyperresponsiveness.

Considering the pathophysiological action of histamine on blood vessels $[17,18]$, this amine may induce both dilatation of the nasal resistance or capacitance blood vessels and increases in nasal capillary permeability. In the present study, the histamine-induced elevation of $\mathrm{s} R \mathrm{aw}$ was transient, with a peak at $10 \mathrm{~min}$ after stimulation in sensitized guinea-pigs; naphazoline, a potent vasoconstrictive $\alpha$-adrenergic, not only completely suppressed the increase in $\mathrm{s} R$ aw induced by histamine but also further potently lowered the spontaneous $\mathrm{s} R$ aw, although not to the extent seen in nonsensitized naphazoline-treated animals. The present experiments regarding plasma extravasation demonstrated that histamine increases vascular permeability into the lamina propria and the luminal entry of sensitized guinea-pigs. This indicates that both blood vessel dilation, to a large degree, and the oedematous response, to a lesser degree, contribute to the elevation of sRaw induced by histamine.

The present nasal hyperresponsiveness to histamine was largely suppressed by the $\mathrm{H}_{1}$ antagonist mepyramine, but not by atropine, which suggests that histamine directly stimulates $\mathrm{H}_{1}$-receptors on the blood vessels inducing the hyperresponse without involving the cholinergic nerve reflex. IRIYOSHI et al. [19] demonstrated increased expression of $\mathrm{H}_{1}$ receptor messenger ribonucleic acid in the nasal mucosa of patients with allergic rhinitis. This has not yet been examined in the present model, but it remains to be clarified whether the hyperresponse is due to the increased number of $\mathrm{H}_{1}$ receptors, enhanced signal transduction in the intracellular events following receptor stimulation or other events. Conversely, it is well known that the acceleration of serous secretion by nasal glandular cells is stimulated directly by cholinergic agonists and indirectly by histamine via the cholinergic nerve reflex. In the present model, it was observed that MCh induced serous secretion in not only sensitized guineapigs but also nonsensitized ones. The increased sRaw induced by nasal instillation of MCh was almost completely blocked by naphazoline, to a level similar to that observed when MCh-untreated guinea-pigs were treated with $\alpha$ stimulant. Furthermore, atropine did not prevent the increase in sRaw induced by histamine. Taking all of these results into consideration, it appears that the serous nasal secretion induced by MCh contributes less to the increased sRaw than the dilation of the nasal vessel, which participate to a large extent in this response.

The degree of the late phase asthmatic response has been suggested to be associated with the degree of increased bronchial responsiveness to stimuli $[20,21]$. It is well known that late phase nasal blockage is also observed after antigen provocation in allergic rhinitis patients [4]. However, the relationship between the late nasal response and the nasal hyperresponsiveness to some stimuli has not yet been clarified. Previous work with the present model has demonstrated that early and late phase increases in $\mathrm{s} R$ aw are evident at the 4th-10th inhalation challenges, but, at the 13th-20th challenges, both biphasic responses are diminished [7]. Differing from these results, the present study indicated that hyperresponsiveness to histamine was still increased at these relatively late challenges. Therefore, it seems that the increase in nasal hyperresponsiveness to histamine is not directly associated with the occurrence of antigen-induced late phase nasal blockage.

In conclusion, an experimental allergic rhinitis model showing potent nasal hyperresponsiveness to histamine has been established. The symptoms elicited are quite similar to clinical cases and more intense than those of other experimental models $[16,22]$, indicating the usefulness of this model for investigations into the occurrence of nasal hyperresponsiveness.

Acknowledgements. The authors gratefully acknowledge S. Suzuki (Torii Pharmaceutical Co. Ltd.) for providing the Japanese cedar pollen.

\section{References}

1. Kanthawatana S, Maturim W, Fooanant S, Manorot M, Trakultivakorn M. Evaluation of threshold criteria for the nasal histamine challenge test in perennial allergic rhinitis. Asian Pac J Allergy Immunol 1997; 15: 65-69.

2. Kirkegaard J, Mygind N, Molgaard F, et al. Ordinary and high-dose ipratropium in perennial nonallergic rhinitis. $J$ Allergy Clin Immunol 1987; 79: 585-590.

3. Tsai JJ, Ho CY, Wang SR. Relationship between nasal resistance and airway hyperreactivity following nasal provocation with Dermatophagoides pteronyssinus in allergic rhinitis. Int Arch Allergy Immunol 1995; 106: 286290.

4. de Graaf-in't Veld C, Garrelds IM, Koenders S, Gerth van Wijk R. Relationship between nasal hyperreactivity, mediators and eosinophils in patients with perennial allergic rhinitis and controls. Clin Exp Allergy 1996; 26: 903-908.

5. Prieto JL, Gutierrez V, Berto JM, Camps B. Sensitivity and maximal response to methacholine in perennial and seasonal allergic rhinitis. Clin Exp Allergy 1996; 26: 6167.

6. Konno A, Togawa K, Nishihira S. Seasonal variation of sensitivity of nasal mucosa in pollinosis. Arch Otorhinolaryngol 1981; 232: 253-261.

7. Nabe T, Mizutani N, Shimizu K, Takenaka H, Kohno S. Development of pollen-induced rhinitis with early and late phase nasal blockage in guinea pigs. Inflamm Res 1998; 47: 369-374. 
8. Nabe T, Shinoda N, Yamashita K, Yamada M, Yamamura $\mathrm{H}$, Kohno S. Comparative studies on nebulizers for antigen inhalation in experimental asthma. Allergol Int 1997; 46: 261-267.

9. Bensadoun A, Weinstein D. Assay of proteins in the presence of interfering materials. Anal Biochem 1976; 70: 241-250.

10. Verra F, Escudier E, Pinchon MC, Fleury J, Bignon J, Bernaudin JF. Effects of local anaesthetics (lidocaine) on the structure and function of ciliated respiratory epithelial cells. Biol Cell 1990; 69: 99-105.

11. Flynn N, O'Toole DP, Bourke E, O'Malley K, Cunningham AJ. The effect of local anaesthetics on epinephrine absorption following rectal mucosal infiltration. Can $J$ Anaesth 1989; 36: 397-401.

12. Nabe T, Shimizu K, Mizutani N, et al. A new model of experimental allergic rhinitis using Japanese cedar pollen in guinea pigs. Jpn J Pharmacol 1997; 75: 243-251.

13. Pennock BE, Cox CP, Rogers RM, Cain WA, Wells JH. A noninvasive technique for measurement of changes in specific airway resistance. $J$ Appl Physiol 1979; 46: 399_ 406.

14. Katayama S, Shionoya H, Ohtake S. A new method for extraction of extravasated dye in the skin and the influence of fasting stress on passive cutaneous anaphylaxis in guinea pigs and rats. Microbiol Immunol 1978; 22: 89101.

15. Iijima H, Ishii M, Yamauchi K, Chao C-L, et al. Bronchoalveolar lavage and histologic characterization of late asthmatic response in guinea pigs. Am Rev Respir Dis 1987; 136: 922-929.

16. Narita S, Asakura K, Kataura A. Effects of thromboxane $\mathrm{A}_{2}$ receptor antagonist (Bay u 3405) on nasal symptoms after antigen challenge in sensitized guinea pigs. Int Arch Allergy Immunol 1996; 109: 161-166.

17. Havas TE, Cole P, Parker L, Oprysk D, Ayiomamitis A. The effects of combined $\mathrm{H}_{1}$ and $\mathrm{H}_{2}$ histamine antagonists on alterations in nasal airflow resistance induced by topical histamine provocation. J Allergy Clin Immunol 1986; 78: $856-860$.

18. Arfors KE, Rutili G, Svensjo E. Microvascular transport of macromolecules in normal and inflammatory conditions. Acta Physiol Scand Suppl 1979; 463: 93-103.

19. Iriyoshi N, Takeuchi K, Yuta A, Ukai K, Sakakura Y. Increased expression of histamine $\mathrm{H}_{1}$ receptor mRNA in allergic rhinitis. Clin Exp Allergy 1996; 26: 379-385.

20. Hargreave FE, Ryan G, Thomson NC, et al. Bronchial responsiveness to histamine or methacholine in asthma: measurement and clinical significance. $J$ Allergy Clin Immunol 1981; 68: 347-355.

21. Cartier A, Thomson NC, Frith PA, Roberts R, Hargreave FE. Allergen-induced increase in bronchial responsiveness to histamine: relationship to the late asthmatic response and change in airway caliber. J Allergy Clin Immunol 1982; 70: 170-177.

22. Gawin AZ, Baraniuk JN, Igarashi Y, Kaliner MA. Effects of capsaicin desensitization on nasal mucosal secretion in guinea pigs in vivo. J Appl Physiol 1993; 75: 798-804. 